\title{
Probiotic Enterococcus durans Interference with Oral Candida albicans Adhesion: An in vitro Study
}

\author{
Mohammad Rashid 1(D), Amjad Ahamadi 2 (D), Rashid Ramazanzadeh 2,3 (D), Bijan Nouri 4 (D), \\ Faranak Shafiee $5 *$ iD
}

1. Student Research Committee, Kurdistan University of Medical Sciences, Sanandaj, Iran

2. Dept. of Microbiology, Faculty of Medicine, Kurdistan University of Medical Sciences, Sanandaj, Iran

3. Cellular and Molecular Research Center, Research Institute for Health Development, Kurdistan University of Medical Sciences, Sanandaj, Iran

4. Social Determinants of Health Research Center, Research Institute for Health Development, Kurdistan University of Medical Sciences, Sanandaj, Iran

5. Dept. of Pediatric Dentistry, Faculty of Dentistry, Kurdistan University of Medical Sciences, Sanandaj, Iran

\begin{tabular}{|c|c|}
\hline \multirow{2}{*}{$\begin{array}{l}\text { Article Info } \\
\text { dof } 10.30699 / \text { jambs.28.130.291 }\end{array}$} & ABSTRACT \\
\hline & Background \& Objective: Candida species, and most frequently isolated \\
\hline $\begin{array}{l}\text { Received: 2020/06/08; } \\
\text { Accepted: 2020/07/21; } \\
\text { Published Online: } 30 \text { Sep 2020; }\end{array}$ & $\begin{array}{l}\text { technique, using probiotics has gained popularity in preventing and controlling } \\
\text { diseases at present. Enterococcus durans has exhibited useful antioxidative } \\
\text { properties and antibacterial and probiotic characteristics. This study aims to }\end{array}$ \\
\hline Use your device to scan and read the & Candida albicans. \\
\hline 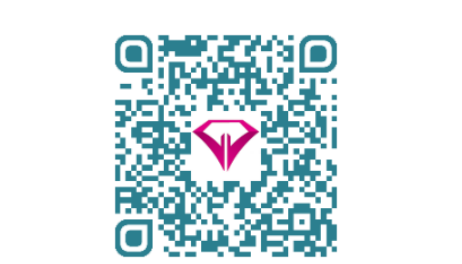 & $\begin{array}{l}\text { Materials \& Methods: Reference bacteria strain of probiotic } E \text {. durans (ATCC } \\
\text { 6056), } C \text {. albicans reference strain (PTCC-5027), and } 10 \text { clinical samples of } C \text {. } \\
\text { albicans were provided. Adherence inhibition of Candida albicans was measured } \\
\text { using microtiter plates applying two methods (addition of a mixed suspension of } C \text {. } \\
\text { albicans and } E \text {. durans simultaneously and addition of } E \text {. durans } 30 \text { minutes before } \\
C \text {. albicans). Data were analyzed with a repeated measure model. Statistical } \\
\text { significance was set at P-value<0.01. }\end{array}$ \\
\hline $\begin{array}{l}\text { Corresponding Information: } \\
\text { Faranak Shafiee, } \\
\text { Dept. of Pediatric Dentistry, Faculty of }\end{array}$ & $\begin{array}{l}\text { Results: Adhesions of } C \text {. albicans biofilms decreased in the presence of the probiotic } \\
\text { strain E. durans. Mean OD } 620 \mathrm{~nm} \text { was within the range of } 0.45 \text { to } 0.49 \text {, and } 0.33 \text { for } \\
\text { OD } 490 \mathrm{~nm} \text {. }\end{array}$ \\
\hline $\begin{array}{l}\text { Dentistry, Kurdistan University of } \\
\text { Medical Sciences, Sanandaj, Iran }\end{array}$ & $\begin{array}{l}\text { Conclusion: Using E. durans as a probiotic could reduce Candida albicans } \\
\text { adhesion and, therefore, can be considered as an effective way to decrease its } \\
\text { pathogenicity. }\end{array}$ \\
\hline faranakshafiee@gmail.com & Keywords: Candida albicans, Enterococcus, Probiotic \\
\hline (c) (1) () & $\begin{array}{l}\text { distributed under the terms of the Creative Commons Attribution-noncommercial } 4.0 \text { International Licen } \\
\text { rccial usages with proper citation. }\end{array}$ \\
\hline
\end{tabular}

\section{Introduction}

Candida species are commensal microorganisms and members of normal oral cavity flora; however, these species are opportunistic pathogens which cause candidiasis under specific conditions (1). Candida albicans (C. albicans) is a microbiologic member of the oral cavity in children with dental caries (2). As reported by Odds, there is a relationship between adhesion rate of $C$. albicans to surfaces and its ability to form colonies and induce diseases (3).

As a new biologic technique, using probiotics has gained popularity in preventing and controlling diseases at present. It is considered as an alternative method to change the microbial ecology of the oral cavity. Competition among probiotics to replace pathogenic microorganisms makes it possible to simultaneously use systemic and local interventions $(4,5)$. The World Health Organization defines probiotic bacteria as viable microorganisms that are useful for the host's health when used appropriately (1). Different microorganisms have been used as probiotics. Lactic acid bacteria (LAB) is one of the most utilized and effective probiotics. Enterococci, as LAB family members, are ubiquitous due to their durability and resistance to growth inhibition factors, including their resistance to high acidity and biliary salts. They are naturally found in different environments including dairy products, meat, vegetables, and cereal (6-8). Also, they are the most predominant microorganisms found in traditional cheese produced from raw milk $(7,9)$. 
Enterococcus Durans (E. durans) is a LAB group bacteria and is on the list of safe materials/agents (GRAS). This bacteria is one of the permanent residents of the gastrointestinal tract (10). Evidence has shown its useful antioxidative, antibacterial, and probiotic characteristics. It has a variety of characteristics, including potential adhesion and colonization of the mucosa, the ability to form biofilms, absence of aggressive potential, few virulence factors, specific antimicrobial properties against pathogens, and inducing immune responses $(9,11,12)$. In addition, growth of this bacterial species in a selenium-rich environment results in selenium concentration in the bacterial cell mass. As a result, this bacterial species might be an alternative source for organic selenium in foodstuffs (12).

This is the first study on the effect of $E$. durans on $C$. albicans. One of the criteria for the selection of probiotic bacteria is adherence to dental tissue as part of biofilm and competition with the growth of cariogenic bacteria (4). Therefore, this study evaluated the effects of probiotic $E$. durans on the adhesion of $C$. albicans in vitro.

\section{Materials and Methods}

\section{Isolation of Candida albicans}

Reference bacteria strain of Candida albicans (PTCC-5027) (Pasteur Institute of Iran) and strains isolated from carious teeth of 31 children aged 6-12 years were used in this study. Children's parents received a complete explanation about the aims and methods of the study and then provided written consent for their children to be included in the study. The inclusion criteria consisted of no use of antimicrobial mouthwashes during the previous month, no use of antifungal agents, antihistamines, corticosteroids, and a caries index of $>10$ as previously reported (13).

Dental plaques were transferred from the carious teeth into Falcon tubes containing $5 \mathrm{~mL}$ of BHI (Brain heart infusion) culture medium (Ibresco Made in Italy) using a sterile microbrush. The tubes were incubated at $37^{\circ} \mathrm{C}$ for 24 hours. The samples were cultured on Mycosel Agar (Quelab Made in $U K$ ) at room temperature for 24 hours. A colony of specimens grown in a Mycosel Agar was sub-cultured in chrome agar Candida (Ibresco) medium to separate $C$. albicans which is observed as green colonies on the culture medium (14).

Positive control samples of $C$. albicans (PTCC5027) and E. durans (ATCC 6056) (Collins et al. Rayen Biotechnology co.) were concomitantly cultured with C. albicans sample isolations.

Formation of Biofilms using the Microtiter Plate Technique

At this stage, the potential of biofilm formation of the clinical samples was determined using the microtiter plate technique. First, 0.5 McFarland concentrations of the clinical and standard samples were prepared in a BHI broth culture medium (based on standard CLSI) (15). Then, $200 \mu \mathrm{L}$ of each suspension were transferred into 96 well plates in a microtiter plate (each sample in one raw with eight repetitions). Negative control well only contained BHI broth culture medium. After 24 hours, the contents of the wells were retrieved, and each well was washed with $200 \mu \mathrm{L}$ of sterile physiologic serum three times. A total of $200 \mu \mathrm{L}$ of ethanol was used in order to adhere bacteria to the wells for 15 minutes. The quantification of clinical isolates biofilm formation was performed using crystal violet (CV) (Merck, Germany) staining method, according to the protocol described by Silva et al (16). In a nutshell, following biofilm formation, the wells were washed with PBS, and CV (1\% v/v) was added to the wells, followed by acetic acid (33\% v/v) (17). An ELISA reader was used to determine the optical density of the $\mathrm{CV}$ stain in the stain solvent at a wavelength of $492 \mathrm{~nm}$. Highly adhering strains with greater capacity to form biofilms were selected for the next stage $(9,18)$.

\section{The Effects of $E$. durans on Inhibiting C. albicans Adhesion}

The effects of E. durans (ATCC 6056) on inhibiting the adherence of clinical isolated $C$. albicans were evaluated using two techniques: by adding $C$. albicans and $E$. durans to the wells simultaneously (technique 1 ), and by adding $E$. durans $30 \mathrm{~min}$ before adding $C$. albicans (technique 2). For each technique, $100 \mu \mathrm{L}$ of a $C$. albicans suspension and $100 \mu \mathrm{L}$ of an E. durans suspension were added to each well (each sample in one raw with eight repetitions). Then, the differences between the optical densities of the control wells (standard $C$. albicans well in association with $E$. durans and E. durans well alone) and the wells containing clinical samples were evaluated to assess the effects of $E$. durans on adherence $(9,18)$.

The isolates were categorized as follows based on their optical density using Stepanovic et al.'s technique $(9,19)$.

\section{Statistical Analysis}

Data were analyzed with SPSS 20 (SPSS Inc., Chicago, IL., USA) using a repeated measure model. Statistical significance was set at $\mathrm{P}$-value $<0.01$.

\section{Results}

\section{Isolation of the Samples and Determination of Adhesion Capacity}

In this in vitro study, 10 of 31 clinical isolated samples were $C$. albicans and 21 samples were other microorganisms. All the isolates exhibited moderate adhesion capacity which was similar to the standard samples. The OD620 $\mathrm{nm}$ range was 0.45 to 0.49 and 0.33 for OD490 nm (Table 1).

\section{The effects of $E$. durans on $C$. albicans Adhesion using Microtiter Plate Technique}

The results were indicative of a significant difference in the potential of adhesion, using both methods (Table). 
Table 1. Comparison of adherence reduction of $C$. albicans clinical isolates in the presence of probiotic $E$. durans

\begin{tabular}{|c|c|c|c|c|}
\hline & $\begin{array}{l}\text { Wavelength } \\
\quad(\mathbf{n m})\end{array}$ & $\begin{array}{c}\text { Mean } \pm \text { SD } \\
\text { (before probiotic) }\end{array}$ & $\begin{array}{c}\text { Mean } \pm \text { SD } \\
\text { (after probiotic) }\end{array}$ & $P$-value \\
\hline \multirow{2}{*}{ Method1 } & 490 & $1.071 \pm 0.416$ & $0.331 \pm 0.038$ & 0.000 \\
\hline & 620 & $0.774 \pm 0.078$ & $0.499 \pm 0.073$ & 0.003 \\
\hline \multirow{2}{*}{ Method2 } & 490 & $1.062 \pm 0.094$ & $0.332 \pm 0.066$ & 0.000 \\
\hline & 620 & $0.775 \pm 0.095$ & $0.452 \pm 0.058$ & 0.001 \\
\hline
\end{tabular}

Mean \pm SD of clinical isolates, P-value $<0.01$ is statistically significant, Method 1: Simultaneous Adding C. albicans \& probiotic, Method 2: Adding C. albicans $30 \mathrm{~min}$ after probiotic.

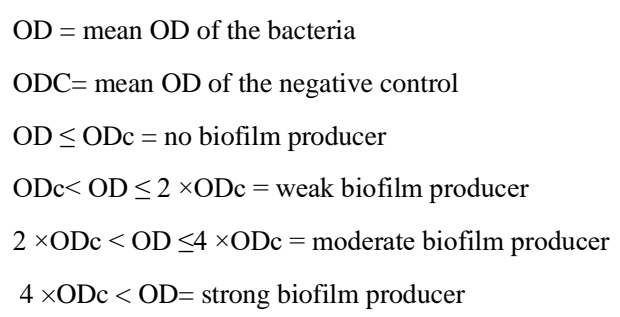

\section{Discussion}

Biofilm formation is the first step in bacterial infections. They are able to attach to the dental lamina and produce destructive material. We aimed to introduce a methods to reduce the biofilm formation in dental caries. C. albicans adhesion to teeth surfaces has a major role in its pathogenicity (20). Therefore adhesion reduction can be an effective way to decrease its detrimental effects (21). present in food and dairy products, Enterococcus strains have been known for a long time as effective probiotics (9). Enterococci are a type of LAB species and are members of the normal flora of the gastrointestinal tract and fermented food (12). A study by Carasi et al. showed that E. durans isolated from kefir were able to inhibit different Grampositive and Gram-negative pathogens (7). Natanzi et al. reported the anti-adherence activity of Lactobacillus acidophilus on C. albicans (21).

Jorgensen et al. (2017) evaluated the antifungal potential of Lactobacillus reuteri (L. reuteri) probiotic bacterial species against six oral candidal species. Spectrophotometry and agar overlay inhibition techniques were used to evaluate the potential of $L$. reuteri to inhibit the growth of yeasts. In addition, $\mathrm{pH}$ values were evaluated using microsensors. The results indicated that $L$. reuteri produced lactic acid and organic acid decreased the $\mathrm{pH}$ of agar culture media and inhibited hyphal morphogenesis induction in Candida species (1). Jiang et al. (2015) evaluated the growth inhibitory effect of probiotic Lactobacilli on oral Candida species. The results indicated that these probiotics had positive effects on oral health (22).

Matsubara et al. (2010) evaluated the inhibitory effects of probiotic Lactobacilli on the early stages of C. albicans biofilm formation. The quality of the biofilm formation was evaluated, and the ultrastructural analyses of biofilms of C. albicans treated with Lactobacillus rhamnosus, Lactobacillus casei, and Lactobacillus acidophilus and their supernatants were carried out. Lactobacilli, depending on the probiotic type and biofilm formation stage, resulted in a significant decrease in the number of cells in biofilms $(P<0.05)$. L. rhamnosus had no significant effect on the maturation of biofilms $(P>0.05)$; however, it resulted in a significant decrease in the early stages of C. albicans biofilms (23).

Hasslof et al. showed the inhibitory effects of commercial samples of probiotic Lactobacilli on oral S. mutans and Candida in vitro. In the mentioned study, all the Lactobacillus species inhibited the growth of Candida and S. mutans samples; however, the inhibitory effects on $C$. albicans were weaker than those of $S$. mutans, which might be attributed to the resistance of pathogenic bacteria (24).

In the present study, inhibitory effects of E. durans on $C$. albicans adhesion were evaluated. Adhesion was evaluated using the microtiter plate technique and the complete culturing of the probiotic agent. In the first technique, adhesion was evaluated by simultaneous addition of the bacteria and $C$. albicans to the culture medium; in the second technique, the probiotic bacteria culture was carried out $30 \mathrm{~min}$ before adding $C$. albicans. Based on the results of the present study, the presence of $E$. durans as a probiotic bacterial species resulted in a decrease in adhesion of $C$. albicans to the test surfaces for both techniques; However, in both techniques, there was a significant decrease in binding, which might be attributed to the inter-surface interactions (cell-to-cell and cell-to-surface) and the production of external metabolites that made the organization and structure of the biofilm unstable $(1,25)$.

Considering the useful systemic effects of E. durans on increasing the secretion of $\operatorname{Ig} \mathrm{A}$, regulating the 
immune system, and increasing the production of IL10 , further clinical studies are warranted $(7,11)$. The results of the present study indicate the positive effects of $E$. durans on decreasing $C$. albicans adhesion.

\section{Conclusion}

Using E. durans as a probiotic could reduce Candida albicans adhesion, which might be attributed to the inter-surface interactions and the release of bioactive substances which make the organization and structure of the biofilm unstable and, therefore, can be an effective way to decrease its pathogenicity.

\section{Ethical considerations}

Ethical issues (Including plagiarism, informed consent, misconduct, data fabrication and/or falsification, double publication and/or submission, redundancy, etc.) have been completely observed by the authors.

\section{Acknowledgments}

This Study, a dentistry students' thesis, was financially supported by Kurdistan University of Medical Sciences vice chancellor for research [grant numbers IR.MUK.REC.1396/302]. We also thank Kurdistan University of Medical Sciences Research Deputy for financial support and their valuable assistance.

\section{Conflict of Interest}

Authors declared no conflict of interest.

\section{References}

1. Jørgensen MR, Kragelund C, Jensen PØ, Keller MK, Twetman S. Probiotic Lactobacillus reuteri has antifungal effects on oral Candida species in vitro. J Oral Microbiol. 2017;9(1):1274582. [DOI:10.1080/20002297.2016.1274582]

2. de Carvalho FG, Silva DS, Hebling J, Spolidorio LC, Spolidorio DMP. Presence of mutans streptococci and Candida spp. in dental plaque/dentine of carious teeth and early childhood caries. Arch Oral Biol. 2006;51(11):1024-8.

[DOI:10.1016/j.archoralbio.2006.06.001]

3. Ellepola A, Samaranayake L. Oral candidal infections and antimycotics. Crit Rev Oral Biol Med. 2000;11(2):172-98 [DOI:10.1177/10454411000110020301]

4. Gomes R, Miyazak M, Filho IJZ. Action of probiotics on oral pathogens: Efficacy and controversies. Constitution. 2015;2:3. [DOI:10.15761/DOCR.1000129]
5. Ghasempour M, Sefidgar A, Gharekhani S, Shirkhani L, Moghadamnia A. Comparison of the effect of probiotic yogurt-drink kefir,\% 0.2 chlorhexidine and $\% \quad 0.2$ sodium fluoride mouthwashes on streptococcus mutans: An In vitro study. J Babol Univ Med Sci. 2013;15(6):812.

6. Suzuki N, Yoneda M, Hatano Y, Iwamoto T, Masuo Y, Hirofuji T. Enterococcus faecium WB2000 inhibits biofilm formation by oral cariogenic Streptococci. Int J Dent. 2011;2011:834151. [DOI:10.1155/2011/834151]

7. Carasi P, Jacquot C, Romanin DE, et al. Safety and potential beneficial properties of Enterococcus strains isolated from kefir. Int Dairy J. 2014;39(1):193-200. [DOI:10.1016/j.idairyj.2014.06.009]

8. Pavli F, Argyri A, Papadopoulou O, Nychas G, Chorianopoulos N, Tassou C. Probiotic potential of lactic acid bacteria from traditional fermented dairy and meat products: Assessment by in vitro tests and molecular characterization. J Prob Health. 2016;4(157):10.4172.

9. Pieniz S, de Moura TM, Cassenego APV, et al. Evaluation of resistance genes and virulence factors in a food isolated Enterococcus durans with potential probiotic effect. Food Control. 2015;51:49-54.

[DOI:10.1016/j.foodcont.2014.11.012]

10. Fijan S. Microorganisms with claimed probiotic properties: an overview of recent literature. Int J Environment Res Pub Health. 2014;11(5):474567. [DOI:10.3390/ijerph110504745]

11. Carasi P, Racedo SM, Jacquot C, Elie AM, Serradell MdlÁ, Urdaci MC. Enterococcus durans EP1 a promising anti-inflammatory probiotic able to stimulate $\operatorname{sg} \mathrm{A}$ and to increase Faecalibacterium prausnitzii abundance. Front Immunol. 2017;8:88 [DOI:10.3389/fimmu.2017.00088]

12. Pieniz S, Andreazza R, Anghinoni T, Camargo F, Brandelli A. Probiotic potential, antimicrobial and antioxidant activities of Enterococcus durans strain LAB18s. Food Control. 2014;37:251-6. [DOI:10.1016/j.foodcont.2013.09.055]

13. Wu N, Lin J, Wu L, Zhao J. Distribution of Candida albicans in the oral cavity of children aged 3-5 years of Uygur and Han nationality and their genotype in caries-active groups. Genet Mol Res. 2015;14(1):748-57. [DOI:10.4238/2015.January.30.18]

14. Ghasempour M, Omran SM, Moghadamnia AA, Shafiee F. Effect of aqueous and ethanolic extracts of Lippia citriodora on candida albicans. 
Electron Physician. 2016;8(8):2752-8. [DOI:10.19082/2752]

15. Humphries RM, Ambler J, Mitchell SL, et al. CLSI Methods Development and standardization working group best practices for evaluation of antimicrobial susceptibility tests. J Clin Microbiol. 2018;56(4). [DOI:10.1128/JCM.01934-17]

16. Silva S, Henriques M, Martins A, Oliveira R, Williams D, Azeredo J. Biofilms of non-Candida albicans Candida species: quantification, structure and matrix composition. Med Mycol. 2009;47(7):681-9. [DOI: $10.3109 / 13693780802549594]$

17. Stepanovic S, Vukovic D, Hola V, et al. Quantification of biofilm in microtiter plates: overview of testing conditions and practical recommendations for assessment of biofilm production by staphylococci. APMIS. 2007;115(8):891-9. [DOI:10.1111/j.16000463.2007.apm_630.x]

18. Tahmourespour A, Kermanshahi RK. The effect of a probiotic strain (Lactobacillus acidophilus) on the plaque formation of oral Streptococci. Bosnian J Basic Med Sci. 2011;11(1):37. [DOI:10.17305/bjbms.2011.2621]

19. Stepanović S, Vuković D, Dakić I, Savić B, Švabić-Vlahović M. A modified microtiter-plate test for quantification of staphylococcal biofilm formation. Journal of microbiological methods. 2000;40(2):175-9. [DOI:10.1016/S01677012(00)00122-6]

\section{How to Cite This Article:}

Rashidi M, Ahmadi A, Ramazanzadeh R, Noori B, Shafiee F. Probiotic Enterococcus durans Interference with Oral Candida albicans Adhesion: An in vitro Study. J Adv Med Biomed Res. 2020; 28 (130) :291-295

\section{Download citation:}

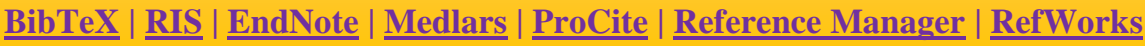

\section{Send citation to:

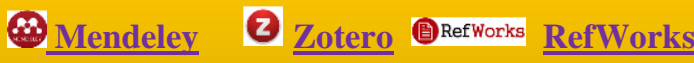

20. Odds F. Candida and candidiosis: a review and bibliography bailliere tindall. London, UK. 1988.

21. Mehrabani Natanzi M, Emampour M, Mirzaei A, Kalantar E, Khodaii Z. Protective Activity of Probiotic Bacteria Against Candida albicans: An In Vitro Study. Int J Enteric Pathog. 2018;6(4):113-7. [DOI:10.15171/ijep.2018.28]

22. Jiang Q, Stamatova I, Kari K, Meurman J. Inhibitory activity in vitro of probiotic lactobacilli against oral Candida under different fermentation conditions. Benef Microbes. 2014;6(3):361-8. [DOI:10.3920/BM2014.0054]

23. Ishikawa KH, Mayer MP, Miyazima TY, et al. A multispecies probiotic reduces oral Candida colonization in denture wearers. J Prosthodontics. 2015;24(3):194-9. [DOI:10.1111/jopr.12198]

24. Hasslöf P, Hedberg M, Twetman S, StecksénBlicks C. Growth inhibition of oral mutans streptococci and candida by commercial probiotic lactobacilli-an in vitro study. BMC Oral Health. 2010;10(1):18. [DOI:10.1186/1472-6831-10-18]

25. Matsubara V, Wang Y, Bandara H, Mayer M. Samaranayake, LP (2016). Probiotic lactobacilli inhibit early stages of Candida albicans biofilm development by reducing their growth, cell adhesion, and filamentation. Apply Microbiol Biotechnol. $100 \quad$ (14): 6415-26. [DOI:10.1007/s00253-016-7527-3] 